\title{
Quality of informed consent for invasive procedures in central Saudi Arabia
}

This article was published in the following Dove Press journal:

International Journal of General Medicine

21 March 2012

Number of times this article has been viewed

\author{
Mostafa A Abolfotouh \\ Abdallah A Adlan \\ King Abdullah International Medical \\ Research Center, King Saud bin \\ Abdulaziz University for Health \\ Sciences, Riyadh, Saudi Arabia
}

Correspondence: Mostafa Abolfotouh Head, Medical Team, Biobanking Section, King Abdullah International Medical Research Center, King Saud bin Abdulzaiz University for Health Sciences, POB 22490, Riyadh I 1426, Saudi Arabia Tel +966 I 2520088 ext I4469 Email mabolfotouh@gmail.com
Background: Informed consent is considered the most important step in clinical interventions. The aims of this study were (1) to assess the quality of informed consent for invasive procedures with regard to consent process and information given about risks and alternative treatments, and (2) to determine patients' attitude toward informed consent at King Abdulaziz Medical City, Riyadh, Saudi Arabia.

Methods: A cross-sectional study was conducted of 162 adult patients in different wards after undergoing surgery or invasive procedures within 1-2 days of signing the informed consent, using a previously validated interview questionnaire. Data on patients' characteristics, type of invasive procedure, and some informed consent-related issues were collected. Multiple linear regression analysis was used to identify the predictors of the percentage mean score of quality of informed consent, and significance was considered at $P \leq 0.05$.

Results: The quality of informed consent was generally poor $(\%$ mean score $=50.98 \pm 17.49$ ). About two-thirds of patients were told during the informed consent process that they have to sign merely as routine, $48 \%$ thought that if they refused the treatment plan they would lose the interest of the treating physician to help them, $42 \%$ thought that by saying no they would lose the good relationship with their physician, and $42.6 \%$ were not interested in having a copy of the informed consent document. Significantly higher quality was predicted when the physicians were the ones who explained the informed consent $(t=4.15, P<0.001)$ and when informed consent was explained to younger patients $(t=2.754, P=0.007)$. The overall attitude of the patients toward the process of informed consent was satisfactory ( $\%$ mean score $=76.31 \pm 7.63$ ).

Conclusion: The results suggest either that patients are not aware of their rights or that physician paternalism is practiced in Saudi Arabia. Cultural barriers should not be an argument to diminish the role of informed consent. Further studies should focus on how the value of autonomy can be appreciated in the Saudi culture.

Keywords: informed consent, quality, invasive procedure, Saudi Arabia

\section{Introduction}

Informed consent is considered the most important step in health-related research and clinical interventions. It has different definitions depending on the purpose of the required consent. The most fundamental definition is Beauchamp's (as cited by Capron ${ }^{1}$ ): “... an autonomous act by a patient or research subject to expressly permit a professional person to perform a medical action on the patient or to include a person in a research project ...".

Informed consent gained acceptance because it was designed to promote personal choice and to prove the absence of coercion and influence. However, recently, informed consent has become similar to a legal document, not to protect the patient but to protect 
the researchers or health care providers against any future lawsuits. ${ }^{2}$ This serious change may shift the implicit value of informed consent from an ethically recommended practice to a legally protective exercise.

Procedures to obtain consent must ensure that the patient understands the nature of his or her condition and the risks and benefits of the proposed treatment and its alternatives, and agrees to it voluntarily. Complex decisions such as surgery or other invasive procedures require a discussion of uncertainties. ${ }^{3}$

To the best of our knowledge, no work has been performed to answer these questions in Saudi Arabia or in the Arabian Gulf area. The aim of this study was to assess the quality of informed consent for invasive procedures from the perspective of patients at King Abdulaziz Medical City (KAMC), Riyadh, Saudi Arabia, through the following: (1) assessment of the level of patient experience and satisfaction regarding the overall informed consent process, (2) description of the patient experience and satisfaction with the information regarding the risks of the invasive procedure and alternative treatment options, and (3) assessment of the attitudes of the patients toward the informed consent process for invasive procedures.

\section{Study design}

The study included a cross-sectional survey of hospitalized patients after surgery or other invasive procedures, regarding their informed consent.

\section{Study setting}

This study was conducted in KAMC, which is a multi-entity tertiary hospital that provides care to over 500,000 patients annually and has more than 1000 beds with an increasing capacity. It was originally built for the medical services of the Saudi National Guard. However, it now serves all Saudi nationals who are in need of tertiary care. KAMC strives to attain the highest clinical research standards to ensure the safety of its patients.

\section{Study population}

The study population was patients undergoing surgery or invasive procedures at KAMC at the time of the study. To assess the quality of their informed consent to the procedure, patients undergoing the following invasive procedures were included: (1) general surgery (eg, cholecystectomy, hernia, colectomy, mastectomy, thyroid and parathyroid surgery, gastrectomy, bariative surgery); (2) obstetrics and gynecology (eg, Cesarean section, termination of pregnancy, dilatation and curettage, myomectomy, hysterectomy, diagnostic laparoscopy); (3) internal medicine (eg, bone marrow, liver or kidney biopsy, angiography, pleural or abdominal puncture, chemotherapy and radiotherapy); and (4) cardiology (eg, cardiac angiography, percutaneous coronary intervention).

\section{Sampling technique}

Based on an assumed 50\% level of patients' attitude and satisfaction toward informed consent for invasive procedures, $7 \%$ precision, and $95 \%$ confidence interval, the calculated sample size was 196 patients. Using a proportional allocation method of sampling, patients who underwent surgical or invasive procedures were selected to represent the different departments and wards at KAMC. All of the patients who agreed to participate in the study during the study period (4 months) constituted the target population of the study until the target sample size was achieved. A total of 196 patients were allocated to represent the different surgical and medical departments of KAMC within this period, with a response rate of $82.6 \%$.

\section{Data collection methods, instruments used, and measurements}

An interview questionnaire that was previously validated and used by Brezis et $\mathrm{al}^{4}$ was applied after minor modifications. The reported experience of overall informed consent process was assessed using 12 statements with the following responses: "Yes", "No", or "Don't remember". A scoring system that ranged from zero to twelve points was applied. The "Yes" answer to a positive statement was given one point, and the "No" answer to a negative statement was given one point. The total score was summed for each patient, and the percent score was calculated.

The reported experience with the information given on risks, alternative treatment options, and preferences about the decision-making process was also assessed using seven statements to which participants responded with "Yes", "No", or "Don't remember". A scoring system was applied. The "Yes" answer to a positive statement was given one point, and the "No" answer to a negative statement was given one point. The total score was summed for each patient, and the percent score was calculated.

The sum of scores of experience with the consent process and information given on risks was calculated for each patient to assess the overall quality of informed consent, and the percentage score was also calculated. The attitude toward the informed consent procedure was assessed by 17 attitudinal statements. Participants responded to each 
statement with "Strongly agree", "Agree", "Neutral", "Disagree", or "Strongly disagree". A scoring system was applied using the Likert five-point scale ranging from 17 to 85 points. The total score was summed for each patient, and the percent score was calculated.

The patients were interviewed in different wards after undergoing their procedures, usually within 1-2 days of having signed their informed consent. The data were collected by different research coordinators and research assistants who were familiar with surveys similar to the one used in the present study. The original questionnaire was translated into Arabic, with back-translation to English, by bilingual professionals for validity and accuracy. The final Arabic version of the questionnaire was validated in a small pilot study prior to this study, as suggested by experts in this research area.

\section{Ethical considerations}

The study protocol (Application No RR09/021) received ethical approval from the Institutional Review Board of the National Guard Health Affairs, Riyadh, Saudi Arabia.

\section{Data analysis}

SPSS software (v 17.0; SPSS Inc, Chicago, IL) was used for data analysis. The $\chi^{2}$ test was used as a test of significance to compare the categorical data. Student's $t$-test was used as a test of significance to compare the numerical data. Multiple regression analysis was used to determine the significant predictors of the overall satisfaction score points. The variables were chosen to be included in the model based on the results of univariate analyses. For all of the statistical analyses, $P<0.05$ was considered significant.

\section{Results}

A total of 162 patients participated in the study ( $72.2 \%$ females). However, outside the obstetrics and gynecology ward, $61.8 \%$ of patients were female. Patients' ages ranged from 18 years to 76 years mean $=38.75$ years \pm 16.01 years. The majority $(73.5 \%)$ had secondary education or higher, with no significant sex difference (Table 1).

With regard to the specialty of the invasive procedure, general surgery ranked first (39.5\%), followed by obstetrics and gynecology (27.2\%) and internal medicine (25.3\%), while cardiology ranked last (approximately 8\%), which consisted of $20 \%$ male and approximately $3 \%$ female with statistically significant sex difference $\left(\chi^{2}=32.0\right.$, df $=3$, $P<0.001$; Table 1).

Informed consent was signed by $80.2 \%$ of the patients in this study, whereas that of the rest of the patients (19.8\%) was signed by another person. Approximately two-thirds of the study sample $(60.5 \%)$ were asked to sign the informed consent by a physician $\left(\chi^{2}=7.13, \mathrm{df}=3, P=0.21\right)$, and the informed consent was explained to two-thirds of the patients by a physician (67\%), again with no statistically significant sex difference $\left(\chi^{2}=0.59\right.$, df $=3, P=0.90$; Table 1$)$.

\section{Patients' satisfaction regarding the experience of the informed consent process}

The percent mean score of satisfaction of experience with the informed consent process was $54.1 \% \pm 17.9 \%$, denoting a reported dissatisfaction regarding the experience, with no significant sex difference (Table 2). Amongst the patients surveyed, two-thirds reported that they were told that their signature for the informed consent was routine (66.5\%), whereas one-third of the patients reported that no time was allowed for them to ask a question (34\%). Although more than half of the patients expressed that they wished they had been consulted by the treating physician before a decision was made, $50 \%$ of the study sample thought that their own decision was not important because the doctor had already decided for them.

\section{Patients' satisfaction with the provision of information to the patient about risks and alternative treatment options}

The mean percent score of the reported experience was $45.1 \% \pm 27.1 \%$, denoting poor satisfaction. In this study, one-third $(35.2 \%)$ of the patients reported that they were not informed about the alternative treatment options, one-quarter (26.5\%) needed extra information but such information was not provided to them, and less than half (48\%) reported that the risks of the procedures were explained to them. Less than $40 \%$ of the patients were able to recall the risks (Table 2).

\section{Overall quality of the informed consent process}

The percent mean score of quality of the informed consent was $50.97 \% \pm 17.49 \%$, denoting poor quality, with no significant sex difference (Table 2). Table 3 shows that after adjusting for all other potential predictor variables, the patient's age $(t=2.754, P=0.007)$ as well as whether the physician explained the informed consent $(t=4.15, P<0.001)$ were the only significant predictors of the quality of informed consent. The quality of informed consent score was significantly higher when the informed consent was explained by the physician and when the patient was younger. 
Table I Distribution of the study sample according to some demographic and informed consent (IC)-related characteristics

\begin{tabular}{|c|c|c|c|c|c|c|c|}
\hline & \multicolumn{2}{|c|}{$\begin{array}{l}\text { Male } \\
(n=45,27.8 \%)\end{array}$} & \multicolumn{2}{|c|}{$\begin{array}{l}\text { Female } \\
(n=117,72.2 \%)\end{array}$} & \multicolumn{2}{|c|}{$\begin{array}{l}\text { Total } \\
(n=162,100 \%)\end{array}$} & \multirow[t]{2}{*}{ Statistical significance } \\
\hline & No & $\%$ & No & $\%$ & No & $\%$ & \\
\hline \multicolumn{8}{|l|}{ Age group (years) } \\
\hline$<40$ & 24 & 53.3 & 70 & 59.8 & 94 & 58 & \\
\hline \multirow[t]{2}{*}{$>40$} & 21 & 46.7 & 47 & 40.2 & 68 & 42 & $\chi^{2}=0.563, P=0.453$ \\
\hline & $40.89 \pm 20.05$ & & $37.93 \pm 14.19$ & & $38.75 \pm 16.01$ & & $t=0.896, P=0.37$ \\
\hline \multicolumn{8}{|l|}{ Education } \\
\hline Less than secondary & 9 & 20.0 & 34 & 29.1 & 43 & 26.5 & \\
\hline Secondary or higher & 36 & 80.0 & 83 & 70.9 & 119 & 73.5 & $\chi^{2}=1.37, P=0.24$ \\
\hline \multicolumn{8}{|c|}{ Specialty of procedure } \\
\hline General surgery & 19 & 42.2 & 45 & 38.5 & 64 & 39.5 & \\
\hline Obstetrics/gynecology & 0 & 0.0 & 44 & 37.6 & 44 & 27.2 & \\
\hline Internal medicine & 17 & 37.8 & 24 & 20.5 & 41 & 25.3 & \\
\hline Cardiology & 9 & 20.0 & 4 & 3.4 & 13 & 8.0 & $\chi^{2}=32.0, \mathrm{df}=3, P<0.001$ \\
\hline \multicolumn{8}{|c|}{ IC was signed by patient himself/herself } \\
\hline & 38 & 84.4 & 92 & 78.6 & 130 & 80.2 & $\chi^{2}=0.693, P=041$ \\
\hline \multicolumn{8}{|c|}{ Patient was asked to sign by whom? (\%) } \\
\hline Physician & 28 & 62.2 & 70 & 59.8 & 98 & 60.5 & \\
\hline Nurse & 12 & 26.7 & 24 & 20.5 & 36 & 22.2 & \\
\hline Others & 5 & 11.1 & 22 & 18.8 & 27 & 16.7 & \\
\hline No one & 0 & 0 & 1 & 0.9 & 1 & 0.6 & $\chi^{2}=7.13, \mathrm{df}=3, P=0.21$ \\
\hline \multicolumn{8}{|l|}{ IC explained by (\%) } \\
\hline Physician & 32 & 71.1 & 77 & 65.8 & 109 & 67.3 & \\
\hline Nurse & 4 & 8.9 & 11 & 9.4 & 15 & 9.3 & \\
\hline Others & 4 & 8.9 & 15 & 12.8 & 19 & 11.7 & \\
\hline No one & 5 & 11.1 & 14 & 12.0 & 19 & 11.7 & $\chi^{2}=0.59, \mathrm{df}=3, P=0.90$ \\
\hline
\end{tabular}

\section{Attitude of patients toward the practice of informed consent}

The percent mean attitude score was $76.3 \% \pm 7.6 \%$, denoting an overall positive attitude (Table 4). The majority (91.3\%) of patients reported that they "Strongly agreed/Agreed" with the statement that "Informed consent must be easy". Additionally, about $93 \%$ of the patients agreed that all risks and alternative treatment options must be fully explained to the patient during the informed consent process and that having enough time for reading the consent form is important. Meanwhile, only $16 \%$ of the patients were not interested in participating in the decision-making process of determining the treatment routes.

However, about three-quarters of the patients (78\% and 74\%) "Strongly agreed/Agreed" with the statements "Using medical jargon intimidates patients" and "Giving too much information scares patients", respectively. More interestingly, the data showed that more than half $(50 \%)$ of the patients disagreed with the importance of having a copy of the signed document. The majority of the patients (70\%) agreed with giving the physician the right to choose for them. Almost half of the patients (47\%) agreed that saying no to the doctor would mean losing their good relationship with the doctor. More than $25 \%$ of the patients agreed that it would be insulting the treating physician to request a second opinion.

\section{Discussion}

Although the principle of systematically seeking consent is universally acknowledged, its effective implementation may be threatened by different circumstances depending on various practices, subjects, and contexts. ${ }^{3}$ This study was a cross-sectional survey of hospitalized patients after surgery or other invasive procedures regarding their informed consent. The results of this study revealed poor quality of informed consent in terms of experience with the informed consent process and the information given on the risks of the invasive procedure and alternative treatment options.

In an ideal informed consent process, patients would be fully informed about the risk involved with the intended treatment plan, and would be given the right to choose an alternative treatment option. ${ }^{2,5}$ However, more than two-thirds of the patients in the present study wished to play a larger part in the decision-making process in determining the treatment plan. Meanwhile, the majority had questions that were not answered, and they were not informed of any alternative 
Table 2 Patients' responses to experience and satisfaction with informed consent (IC) process and to the information given about the risks and alternative treatment options

\begin{tabular}{|c|c|c|c|}
\hline \multirow[t]{2}{*}{ Statement } & \multicolumn{3}{|l|}{ Responses } \\
\hline & $\begin{array}{l}\text { Yes } \\
\text { n (\%) }\end{array}$ & $\begin{array}{l}\text { No } \\
\text { n (\%) }\end{array}$ & $\begin{array}{l}\text { Don't know } \\
\text { n (\%) }\end{array}$ \\
\hline \multicolumn{4}{|l|}{ (A) Satisfaction with IC process } \\
\hline I. I was told my signature was just routine* & $107(66.5)$ & $46(28.6)$ & $8(4.9)$ \\
\hline 2. The IC explanation was not enough* & $56(34.6)$ & $100(61.7)$ & $6(3.7)$ \\
\hline 3. No time was allowed for questions* & $55(34)$ & $103(63.6)$ & $4(2.4)$ \\
\hline $\begin{array}{l}\text { 4. I was not asked to repeat the consent to make sure that } \\
\text { I understood its contents* }\end{array}$ & $55(34)$ & $104(64.2)$ & $3(1.8)$ \\
\hline 5. I had the chance to ask questions & $113(70.2)$ & $38(23.6)$ & $10(6.2)$ \\
\hline 6. I was given a copy of the document I signed & $13(8)$ & $144(88.9)$ & $5(3.1)$ \\
\hline 7. It had different information from what I was originally told & $25(15.6)$ & $110(68.8)$ & $25(15.6)$ \\
\hline 8. I accepted and signed fully convinced & $142(87.7)$ & $14(8.6)$ & $6(3.7)$ \\
\hline $\begin{array}{l}\text { 9. My decision is not important because my doctor has already } \\
\text { decided on the proper treatment plan* }\end{array}$ & $82(50.6)$ & $77(47.5)$ & $3(1.9)$ \\
\hline 10. Somebody else made sure of my decision & $145(89.5)$ & $17(10.5)$ & \\
\hline II. I was not educated about my treatment plan* & $59(36.4)$ & $94(58.0)$ & $9(5.6)$ \\
\hline 12. I wish I had been consulted by the doctor* & $69(42.6)$ & $87(53.7)$ & $6(3.7)$ \\
\hline \multicolumn{4}{|l|}{$\%$ mean score (standard deviation) $54.14 \pm 17.88$} \\
\hline \multicolumn{4}{|c|}{ (B) Satisfaction with information given about the risks and alternative treatment options } \\
\hline I. The risks were explained to me & $78(48.1)$ & $81(50.0)$ & $3(1.9)$ \\
\hline 2. I needed extra information and it was not given* & $43(26.5)$ & $116(71.6)$ & $3(1.9)$ \\
\hline 3. I was given a plan to treat the risks & $46(28.4)$ & $107(66)$ & $9(5.6)$ \\
\hline 4. I was given a contact if I needed it & $66(40.8)$ & $88(54.3)$ & $8(4.9)$ \\
\hline 5. The patient was able to recall the risks & $63(38.9)$ & $30(18.5)$ & $69(42.6)$ \\
\hline 6. I was not informed about the alternative treatment options* & $57(35.2)$ & $99(61.1)$ & $6(3.7)$ \\
\hline 7. The patient was able to recall the alternative treatment options & $43(26.5)$ & $28(17.3)$ & $91(56.2)$ \\
\hline \multicolumn{4}{|l|}{$\%$ mean score (standard deviation) $45.06 \pm 27.14$} \\
\hline Overall \% mean score of quality (standard deviation) $50.98 \pm 17.49$ & & & \\
\hline
\end{tabular}

Note: *Score was calculated as a negative statement.

treatment options. This finding is in agreement with other previous studies. ${ }^{5-7}$ This may suggest the importance of revisiting the autonomy issue in the Saudi population.

Our results showed that a higher quality of informed consent was predicted when the physician was the one who explained the informed consent. This finding was in

Table 3 Multiple regression analysis of the predictors of quality of informed consent for invasive procedures

\begin{tabular}{|c|c|c|c|c|}
\hline Predictor & $\beta$ & $\begin{array}{l}\text { Standard } \\
\text { error }\end{array}$ & t-value & $P$ value \\
\hline Age & -0.243 & 0.088 & 2.754 & $0.007 *$ \\
\hline Sex $($ male $=I)$ & -2.373 & 2.954 & 0.062 & 0.423 \\
\hline $\begin{array}{l}\text { Education (secondary } \\
\text { or more }=\mathrm{I} \text { ) }\end{array}$ & 1.317 & 3.023 & 0.436 & 0.664 \\
\hline Specialty of procedure & 1.545 & 1.414 & 1.093 & 0.276 \\
\hline $\begin{array}{l}\text { Signed personally } \\
(\text { yes }=I)\end{array}$ & 0.049 & 3.395 & 0.014 & 0.989 \\
\hline $\begin{array}{l}\text { Asked to sign by physician } \\
(y e s=1)\end{array}$ & -4.114 & 3.318 & 1.240 & 0.217 \\
\hline $\begin{array}{l}\text { Explanation by physician } \\
(\text { yes }=1)\end{array}$ & 13.897 & 3.348 & 4.150 & $<0.00 I^{*}$ \\
\hline Constant & 50.065 & 5.277 & 9.487 & $<0.000$ I \\
\hline
\end{tabular}

Note: $*$ is statistically significant. agreement with that of another study, which suggested that clinicians should explain the informed consent 1 day prior to the procedure day. ${ }^{8}$ This could be due to the high anxiety level of the patients who are scheduled to undergo an invasive procedure. Such anxiety reveals a vulnerable situation for the patient, who may be looking for any kind of help. This attitude may suggest that physicians should be conservative regarding the level of information given about the risks. An interesting approach would be to ask the patients how much information they want. ${ }^{9}$ Clinical ethicists have proposed that the informed consent process should be made patient specific. ${ }^{10}$

Autonomy in Western-based ethics is rated as the most important value, and there is a thin line between ethical and nonethical practice. ${ }^{2}$ In other cultures, autonomy is not the first patient concern, and the dispirited need for medical attention is far more important than any philosophical value. ${ }^{11}$ In the present study, a striking finding was that more than $50 \%$ of our study population believed that their decision was not important because the physician had already decided for them. This finding was in agreement with that of another 
Table 4 Five-point Likert scale of the patients' attitude toward the practice of informed consent (IC)

\begin{tabular}{|c|c|c|c|c|c|}
\hline Statement & $\begin{array}{l}\text { Strongly agree } \\
(n, \%)\end{array}$ & $\begin{array}{l}\text { Agree } \\
(n, \%)\end{array}$ & $\begin{array}{l}\text { Not sure } \\
(n, \%)\end{array}$ & $\begin{array}{l}\text { Disagree } \\
(n, \%)\end{array}$ & $\begin{array}{l}\text { Strongly disagree } \\
(n, \%)\end{array}$ \\
\hline I. The explanation must be easy and thorough & $95(58.7)$ & $53(32.7)$ & $6(3.7)$ & $8(4.9)$ & \\
\hline 2. Using medical jargon intimidates patients* & $68(42.2)$ & $58(36.0)$ & $7(4.4)$ & $27(16.8)$ & I (0.6) \\
\hline 3. Too much information scares patients* & $68(42.0)$ & $51(31.5)$ & $6(3.7)$ & $36(22.2)$ & I (0.6) \\
\hline 4. All risks need to be explained to the patient & $103(63.6)$ & $48(29.6)$ & $\mathrm{I}(0.6)$ & $10(6.2)$ & \\
\hline $\begin{array}{l}\text { 5. It is important to repeat the explanation if the } \\
\text { patient demands it }\end{array}$ & $104(64.2)$ & $49(30.2)$ & $4(2.5)$ & $5(3.1)$ & \\
\hline 6. All alternative treatment options must be explained & $108(66.6)$ & $46(28.4)$ & $3(1.9)$ & $5(3.1)$ & \\
\hline 7. It is important to know the plan for emergencies & $102(63.0)$ & $53(32.7)$ & $4(2.5)$ & $3(1.8)$ & \\
\hline $\begin{array}{l}\text { 8. It is important to have someone to contact in case } \\
\text { of emergencies }\end{array}$ & $122(75.8)$ & $30(18.6)$ & $4(2.5)$ & $5(3.1)$ & \\
\hline 9. It is important to have enough time to read the IC & $108(66.7)$ & $42(25.9)$ & $4(2.5)$ & $8(4.9)$ & \\
\hline 10. It is important to have answers to all my questions & II 4 (70.4) & $42(25.9)$ & $4(2.5)$ & $\mathrm{I}(0.6)$ & I $(0.6)$ \\
\hline II. It is not important to have a copy of the IC* & II (6.8) & $71(43.8)$ & II (6.8) & $52(32.1)$ & $17(10.5)$ \\
\hline $\begin{array}{l}\text { 12. Patients should delegate the right of decision } \\
\text { making to the doctor* }\end{array}$ & $47(29.2)$ & $66(41.0)$ & $9(5.6)$ & $38(23.6)$ & I $(0.6)$ \\
\hline 13. I want to choose my route of treatment & $67(4 \mid .4)$ & $67(41.4)$ & $17(10.5)$ & $9(5.5)$ & $2(1.2)$ \\
\hline $\begin{array}{l}\text { 14. If I say no, I might lose the good relationship } \\
\text { with my doctor* }\end{array}$ & $37(23.1)$ & $31(19.4)$ & $28(17.5)$ & $57(35.6)$ & $7(4.4)$ \\
\hline $\begin{array}{l}\text { 15. Saying no means I will not continue having } \\
\text { the same great treatment* }\end{array}$ & $35(21.6)$ & $43(26.5)$ & $24(14.8)$ & $55(34)$ & $5(3.1)$ \\
\hline 16. It is better to have a second opinion & $65(40.2)$ & $5 I(31.5)$ & 19 (II.7) & $25(15.4)$ & $2(1.2)$ \\
\hline 17. It is insulting to ask for a second opinion* & $16(9.9)$ & $27(16.7)$ & $17(10.5)$ & $85(52.4)$ & $17(10.5)$ \\
\hline$\%$ mean score (standard deviation) $76.31 \pm 7.63$ & & & & & \\
\hline
\end{tabular}

Note: *Score was calculated as a negative statement.

study conducted in Pakistan, which found that 56\% reported the same belief. ${ }^{6}$ This result begs the question of whether this acceptance was due to the paternalistic approaches from the physician or due to the fear and submission factor of desperation from the patient side. The majority of the present study sample were females, and this might have contributed to this finding of a paternalistic society.

Although it is important to observe and respect the values of different cultures, these values should not infringe upon fundamental freedoms. In the present study, more than $50 \%$ of the study sample trusted the physician to decide for them, and another half were not interested in having a copy of the informed consent document. This finding may reflect an absolute trust to the extent that consent to what is proposed is not a matter for discussion. It was interesting to see that in spite of the poor quality of informed consent, the overall attitude was positive. This finding could be justified by the possibility that patients' assessment may be affected by the appreciation of having free medical attention in a prestigious tertiary care facility.

The present study has some limitations. First, the study was conducted in one hospital, and it may be difficult to generalize our findings. Second, the assessment of informed consent quality was based on the subjective perception by the patients 1-2 days after they had signed the consent, rather than based on the observation of the actual discussion occurring during the informed consent process. Third, the patients were interviewed shortly after their procedures, and such settings may skew the patient's assessment of his or her experience positively or negatively according to the outcome of the intervention. Fourth, we cannot be certain of the causal direction of the associations observed between the quality of informed consent and other variables, such as the patient's age, attitude, and satisfaction with his or her decision to consent, due to the study's cross-sectional design. It would be desirable to perform a longitudinal study in the future.

Aside from these limitations, the results of this study suggest either that patients are not aware of their rights or that physician paternalism is practiced in Saudi Arabia. The quality of informed consent was revealed to be poor, which requires further research. The best quality was achieved when physicians were the people who explained the form. The patients' attitude toward the process of informed consent was satisfactory. The majority of the patients were satisfied/ extremely satisfied with their decision to consent.

The following is to be recommended: (1) educating the health care givers, including physicians, of the importance of informed consent so that they stop rating it as just routine; 
(2) giving the patient space and respect so that he/she can choose for himself/herself without coercion, making sure that they are aware of the procedures and associated risks they are going to face and how to cope with them, allowing them to keep a copy of whatever document they sign, and increasing their awareness of their rights; and (3) conducting larger and multicenter longitudinal studies.

\section{Acknowledgments}

The authors are indebted to the research team of research coordinators who helped with data collection: Ms Aisha Mahfouz, Ms Edwina Ford, Ms Lubna Saleh, Dr Naila Shaheen, and Ms Samar Alsaleh. Special thanks go to Professor Amin Kashmeery, Head of Bioethics Section and Director of Master of Bioethics Program at King Abdullah International Medical Research Canter (KAIMRC), King Saud bin-Abdulaziz University for Health Sciences, Riyadh, Saudi Arabia, for his continuous support. The authors also thank the editing service office at KAIMRC for the English language editing of the manuscript via a specialist English language copy editor (American Journal Experts).

\section{Disclosure}

The authors report no conflicts of interest in this work.

\section{References}

1. Capron AM. The right to die: progress and peril. Euthan Rev. 1987;2(12):41-59.

2. Corfield L, Pomeroy A. Preoperative consent: how to make sure your practice is legal. Part two. J Perioper Pract. 2008;18(9): 392,394-392,395.

3. UNESCO. Report of the International Bioethics Committee of UNESCO (IBC) on consent. SHS/EST/CIB08-09/2008/1 C UNESCO 2008. Available from: http://unesdoc.unesco.org/ images/0017/001781/178124e.pdf. Accessed February 23, 2012.

4. Brezis M, Israel S, Weinstein-Birenshtock A, Pogoda P, Sharon A, Tauber R. Quality of informed consent for invasive procedures. Int J Qual Health Care. 2008;20(5):352-357.

5. O'Neill O. Some limits of informed consent. J Med Ethics. 2003; 29(1):4-7.

6. Amir M, Rabbani MZ, Parvez MB. Informed consent in elective surgical procedures: "what do the patients think"? J Pak Med Assoc. 2009;59(10):679-682.

7. Berman L, Curry L, Gusberg R, Dardik A, Fraenkel L. Informed consent for abdominal aortic aneurysm repair: the patient's perspective. J Vasc Surg. 2008;48(2):296-302.

8. Little M, Jordens CF, McGrath C, Montgomery K, Lipworth W, Kerridge I. Informed consent and medical ordeal: a qualitative study. Intern Med J. 2008;38(8):624-628.

9. Edwards A. Flexible rather than standardised approaches to communicating risks in health care. Qual Saf Health Care. 2004;13: 169-170.

10. Jonsen AR, Siegler M, Winslade WJ. Clinical Ethics: A Practical Approach to Ethical Decisions in Clinical Medicine. 6th ed. New York: McGraw Hill, Medical Publishing Division; 2006.

11. Kirsch M. The myth of informed consent. Am J Gastroenterol. 2000; 95(3):588-589.
International Journal of General Medicine

\section{Publish your work in this journal}

The International Journal of General Medicine is an international, peer-reviewed open-access journal that focuses on general and internal medicine, pathogenesis, epidemiology, diagnosis, monitoring and treatment protocols. The journal is characterized by the rapid reporting of reviews, original research and clinical studies across all disease areas.

\section{Dovepress}

A key focus is the elucidation of disease processes and management protocols resulting in improved outcomes for the patient.The manuscript management system is completely online and includes a very quick and fair peer-review system. Visit http://www.dovepress.com/ testimonials.php to read real quotes from published authors. 